\title{
Enhancement of the Schottky Barrier Height using a Nitrogen-Rich Tungsten Nitride Thin Film for the Schottky Contacts on AIGaN/GaN Heterostructures
}

\author{
CHUNG-YU LU,${ }^{1}$ EDWARD YI CHANG,,${ }^{1,3}$ JUI-CHIEN HUANG,${ }^{1}$ \\ CHIA-TA CHANG, ${ }^{1}$ MEI-HSUAN LIN,${ }^{1}$ and CHING-TUNG LEE ${ }^{2}$
}

1.-Department of Materials Science and Engineering, National Chiao-Tung University, 1001 Ta-Hsueh Rd., Hsin-Chu 30050, Taiwan, Republic of China. 2.-Department of Electrical Engineering, National Cheng Kung University, Tainan 701, Taiwan, Republic of China. 3.-e-mail: edc@mail.nctu.edu.tw

\begin{abstract}
Tungsten, stoichiometric $\mathrm{W}_{2} \mathrm{~N}$, and nitrogen-rich $\mathrm{W}_{2} \mathrm{~N}$ films were used as Schottky contacts on AlGaN/GaN heterostructures. The nitrogen content in the film was controlled by varying the nitrogen-to-argon gas flow ratio during the reactive sputter deposition. The diode with the nitrogen-rich film exhibited a higher Schottky barrier height and the leakage current was comparable to that of the Ni/Au Schottky contact. Analysis suggested that this was due to the increase of the tungsten nitride work function as the result of higher nitrogen incorporation. Furthermore, after $600^{\circ} \mathrm{C}$ thermal annealing, the diode was stable and showed no change in the leakage current.
\end{abstract}

Key words: $\mathrm{AlGaN} / \mathrm{GaN}$ heterostructures, tungsten nitride, Schottky contacts

\section{INTRODUCTION}

$\mathrm{AlGaN} / \mathrm{GaN}$ heterostructures have shown promise for high-frequency and high-power applications due to their unique properties, including high electron mobility, high carrier concentration, and high breakdown voltage. The potential of this material system was already demonstrated by $\mathrm{AlGaN} / \mathrm{GaN}$ high-electron-mobility transistors (HEMTs) with a very high-power density of $32 \mathrm{~W} / \mathrm{mm}$ at $4 \mathrm{GHz}{ }^{1}$ The Schottky contact is an essential part of these devices, acting as a metal gate to control the current in the two-dimensional electron gas (2DEG). The requirements for the gate metal include high Schottky barrier height, low leakage current, and good thermal stability. Since the Fermi level is not pinned at the surface, high-work-function metals such as $\mathrm{Pt},{ }^{2} \mathrm{Ni},{ }^{3} \mathrm{Pd},{ }^{4} \mathrm{~W}$, silicides $\left(\mathrm{NiSi}^{5}\right.$ and $\left.\mathrm{WSi}_{x}{ }^{6}\right)$, nitrides (TaN, ${ }^{7} \mathrm{WN}_{x}, \mathrm{TiWN}_{x}{ }^{8}$ ), and $\mathrm{ZrB}_{2}{ }^{9}$ have been investigated for their feasibility as Schottky metals on $\mathrm{GaN}$.

(Received July 12, 2007; accepted January 7, 2008;

published online February 7, 2008)
The previous work on the tungsten nitride $\left(\mathrm{WN}_{x}\right)$ Schottky contact on $n$-GaN demonstrated good thermal stability. ${ }^{8}$ However, the characteristics of the $\mathrm{WN}_{x}$ Schottky contact on AlGaN could be different and have never been investigated. Furthermore, recent studies on $\mathrm{WN}_{x}$ showed a variable work function, possibly influenced by either different nitrogen content in the film ${ }^{10}$ or by the change of phase and grain size. ${ }^{11}$ These issues have not been fully addressed in the previous studies but could contribute to different values of the Schottky barrier height and alter the electrical characteristics of the diodes.

In this work, pure tungsten, stoichiometric $\mathrm{W}_{2} \mathrm{~N}$, and nitrogen-rich $\mathrm{W}_{2} \mathrm{~N}$ films were used as Schottky contacts on $\mathrm{AlGaN} / \mathrm{GaN}$ heterostructures, and their properties were characterized and compared with the conventional $\mathrm{Ni} / \mathrm{Au}$ contact.

\section{EXPERIMENTAL}

The AlGaN/GaN heterostructures consisted of $12-\mu \mathrm{m}$-thick undoped GaN buffer on sapphire, followed by $30 \mathrm{~nm} \mathrm{Al}_{0.25} \mathrm{Ga}_{0.75} \mathrm{~N}$. The mobility and 
sheet carrier concentration were $1200 \mathrm{~cm}^{2} / \mathrm{V} \mathrm{s}$ and $1.0 \times 10^{13} \mathrm{~cm}^{-2}$, respectively. $\mathrm{Ti} / \mathrm{Al} / \mathrm{Ni} / \mathrm{Au}$ were evaporated and annealed at $800^{\circ} \mathrm{C}$ to form ohmic contacts. Schottky contacts were defined by lithography, with a circular region of $50 \mu \mathrm{m}$ in diameter. The tungsten nitride was deposit by a direct-current (DC) magnetron reactive sputter deposition system using a pure tungsten target $(99.99 \%)$. Prior to deposition, the chamber was pumped down to a base pressure of $1 \times 10^{-6}$ Torr, and then presputtered for $10 \mathrm{~min}$. The total pressure during the deposition was maintained at $5 \mathrm{~m}$ Torr, while the DC power was fixed at a relatively low value of $30 \mathrm{~W}$ to minimize the possible plasma damages to the surface. The films were deposited with pure nitrogen and the nitrogen-to-argon gas flow ratio $\left(\mathrm{N}_{2} / \mathrm{Ar}\right)$ of 0.2 and 0.5 .

Conventional Schottky metals Ni/Au $(20 \mathrm{~nm} /$ $200 \mathrm{~nm}$ ) were also deposited using an electron-beam evaporator on the AlGaN/GaN heterostructures for comparison with the tungsten nitride Schottky diodes. The fabricated diodes were measured by using a Agilent 4142B modular DC source before and after annealing at different temperatures varying from $300^{\circ} \mathrm{C}$ to $800^{\circ} \mathrm{C}$ with an annealing time of $1 \mathrm{~min}$. The barrier height and the ideality factor were derived from the forward-biased region using thermionic emission theory ${ }^{12}$; the reverse voltage was biased up to $-15 \mathrm{~V}$.

The relationship between the Schottky diode characteristics and the film composition and structure were also investigated. The nitrogen content was determined by X-ray photoemission spectroscopy (XPS) on a Thermo Microlab 350 Auger/XPS system with $\mathrm{Mg} \mathrm{K} \alpha$ radiation (1253.6 eV). The phases and the grain size of the thin films were characterized by X-ray diffraction on a Bede D1 diffractometer. The metal work function was measured by using a Riken Keiki AC-2 photoelectron spectrometer.

\section{RESULTS AND DISCUSSION}

The Schottky barrier heights and ideality factors of the diodes are presented in Table I, each value in the table being an average over five diodes. The barrier height increases as the nitrogen ratio increases in the deposition process. The highest barrier height of $1.21 \mathrm{eV}$ was found for a gas flow ratio of 0.5 . Meanwhile, the ideality factors were below 1.5 for all the samples. For comparison, the Schottky barrier height and the ideality factor of the $\mathrm{Ni} / \mathrm{Au}$ Schottky diode were $1.37 \mathrm{eV}$ and 1.16,

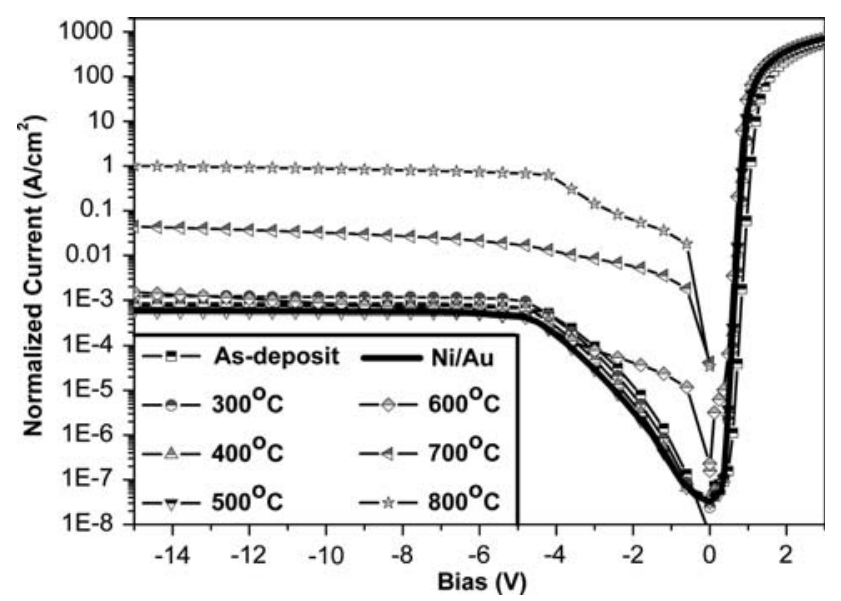

Fig. 1. Normalized $I-V$ characteristics of the as-deposit $\mathrm{Ni} / \mathrm{Au}$ Schottky diodes and the $\mathrm{WN}_{x}$ diodes with deposition condition of $\mathrm{N}_{2} / \mathrm{Ar}=0.5$, after annealing at various temperatures.

respectively, as listed in Table I. From the currentvoltage characteristics in Fig. 1 , the $\mathrm{WN}_{x}$ Schottky diode deposited with the gas flow ratio of 0.5 has a similar value of leakage current as the $\mathrm{Ni} / \mathrm{Au}$ Schottky diode. The increase in the reverse leakage current was apparent only after annealed at $700^{\circ} \mathrm{C}$, which implies a stable interface below this temperature.

To clarify the role of the nitrogen gas flow ratio on the Schottky diode characteristics, the nitrogen content in the film was determined by XPS. Highresolution scans were carried out to calculate the $\mathrm{W} / \mathrm{N}$ ratio using the $\mathrm{W} 4 \mathrm{f}$ and the $\mathrm{N} 1 \mathrm{~s}$ peaks. Figure $2 \mathrm{a}$ and $\mathrm{b}$ shows the $\mathrm{W}$ 4f signal of the film. These figures reveal that the surface was covered with oxides, possibly $\mathrm{WO}_{3}$, before the Ar-ion etch. After the etch, the W $4 \mathrm{f}$ peak, which is related to the oxide, decreases. Meanwhile the $\mathrm{W} 4 \mathrm{f}_{2 / 7}$ peak located at $31.65 \mathrm{eV}$ and the $\mathrm{W} 4 \mathrm{f}_{2 / 5}$ peak located at $33.52 \mathrm{eV}$ dominate. These values are close to the reported value of $31.4 \mathrm{eV}$ for the $\mathrm{W} 4 \mathrm{f}_{2 / 7}$ peak and $33.58 \mathrm{eV}$ for the $\mathrm{W} 4 \mathrm{f}_{2 / 5}$ peak of the $\mathrm{W}_{2} \mathrm{~N}$. ${ }^{13}$ The $\mathrm{N} 1 \mathrm{~s}$ signal is shown in Fig.2c and d; the signal has two peaks before the ion etch, located at $398.5 \mathrm{eV}$ and $402 \mathrm{eV}$, respectively. The former peak is related to bonded $\mathrm{N} 1 \mathrm{~s}$, as the latter is attributed by the unbounded nitrogen in the surface or trapped between the grain boundaries. After the ion etch, these unbounded nitrogen escaped from the surface and only the bonded peak remained. Compositions of the samples were calculated by the area ratio of

Table I. Properties of the $\mathrm{WN}_{x}$ and Ni/Au Schottky Diodes

\begin{tabular}{|c|c|c|c|c|}
\hline Conditions & Barrier Height (eV) & Ideality Factor & Grain Size (nm) & Nitrogen Content (\%) \\
\hline Tungsten & 0.89 & 1.15 & & \\
\hline $\mathrm{WN}_{x}$, gas flow ratio 0.2 & 1.07 & 1.42 & 11.2 & 34 \\
\hline $\mathrm{WN}_{x}$, gas flow ratio 0.5 & 1.21 & 1.24 & 10.2 & 48 \\
\hline $\mathrm{Ni} / \mathrm{Au}$ & 1.37 & 1.16 & & \\
\hline
\end{tabular}



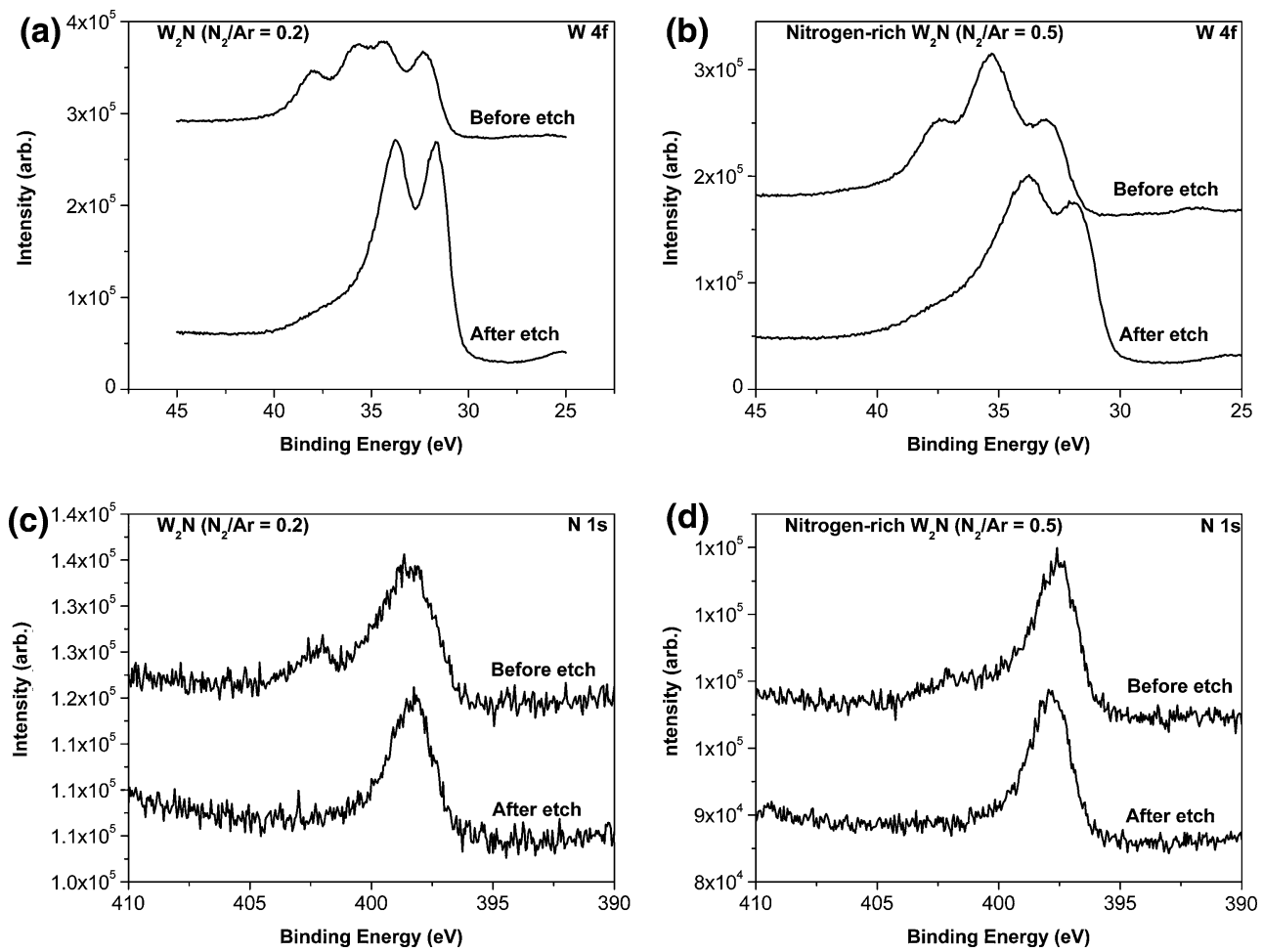

Fig. 2. XPS spectra of the $W_{N}$ film before and after Ar-ion etch. The deposition condition was $N_{2} / A r=0.2$ in $(a, c)$ and $N_{2} / A r=0.5$ in $(b$, d).

the $\mathrm{W} 4 \mathrm{f}$ peak to the $\mathrm{N} 1 \mathrm{~s}$ peak after peak fitting and deconvolution by using XPSpeak 4.1. The relative sensitivity factor, electron transmission function, and mean free path were also taken into consideration. The nitrogen content in the film with the gas flow ratio of 0.2 corresponds to stoichiometric $\mathrm{W}_{2} \mathrm{~N}$ and more nitrogen is incorporated into the film with the gas flow ratio of 0.5 ; values are listed in Table I.

Figure 3 shows the X-ray diffraction patterns of these samples. $\mathrm{W}_{2} \mathrm{~N}$ is the dominating phase except for pure tungsten. The peak position of $\mathrm{W}_{2} \mathrm{~N}$ (111) in the sample with stoichiometric $\mathrm{W}_{2} \mathrm{~N}$ is $37.4 \mathrm{deg}$, and the peak for the nitrogen-rich $\mathrm{W}_{2} \mathrm{~N}$ shifts to a much lower value of $36.88 \mathrm{deg}$, the larger deviation from

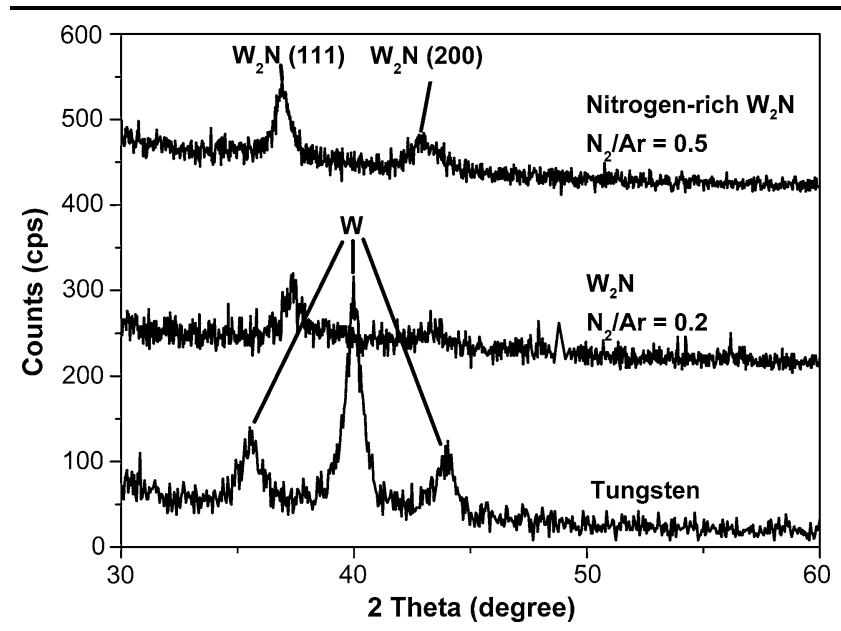

Fig. 3. An X-ray diffraction scan of the $\mathrm{WN}_{x}$ films and the tungsten film. the ideal value of 37.7 deg for $\mathrm{W}_{2} \mathrm{~N}(111)^{14}$ in the latter is possibly due to the excessive nitrogen incorporation in the interstitial sites that resulted in the lattice expansions. ${ }^{15}$ The crystal grain size was calculated using Scherrer's formula. ${ }^{16}$ The average grain size was $11.2 \mathrm{~nm}$ and $10.3 \mathrm{~nm}$ for the samples with the stoichiometric $\mathrm{W}_{2} \mathrm{~N}$ and the nitrogen-rich $\mathrm{W}_{2} \mathrm{~N}$, respectively. The photoemission spectra of the films are shown in Fig. 4. The work function is $4.5 \mathrm{eV}$ for tungsten, $4.62 \mathrm{eV}$ for stoichiometric $\mathrm{W}_{2} \mathrm{~N}$, and increased to $4.88 \mathrm{eV}$ for nitrogenrich $\mathrm{W}_{2} \mathrm{~N}$.

Based on the above results, high nitrogen partial pressure in the chamber during the deposition process evidently resulted in the $\mathrm{W}_{2} \mathrm{~N}$ film with high nitrogen contents. The excessive nitrogen was trapped in the interstitial sites and expanded the lattice. From the work function measurement, the value increases as the nitrogen is further incorporated. Contrary to the report by Jiang et al., ${ }^{11}$ the grain size and phase were similar and did not contribute to the change of the work function. Thus, it is suggested that the change of the work function in the $\mathrm{W}_{2} \mathrm{~N}$ film was due to the excessive nitrogen content of the film which caused compositional change and the lattice parameter expansion. The Schottky barrier height benefits from this nitrogen content enhancement and increases.

\section{CONCLUSION}

Schottky diodes with high barrier height and low leakage current were fabricated using the 

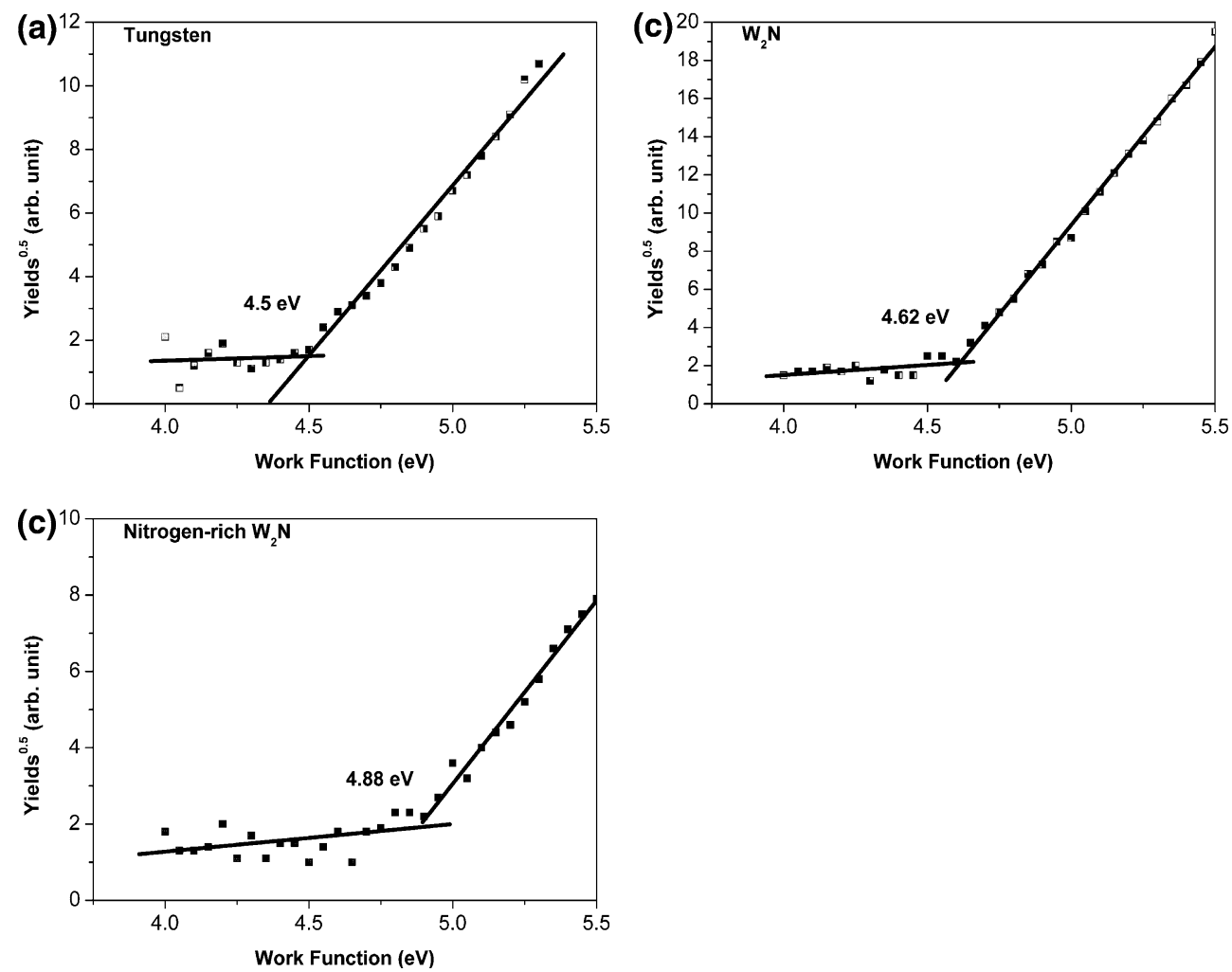

Fig. 4. Photoemission spectra of the $\mathrm{WN}_{x}$ films and the tungsten film.

nitrogen-rich $\mathrm{W}_{2} \mathrm{~N}$ film on the $\mathrm{AlGaN} / \mathrm{GaN}$ heterostructures. The degradation of the diode characteristics was not observed up to $600^{\circ} \mathrm{C}$. Results also indicate a strong relationship between the nitrogen content in the $\mathrm{W}_{2} \mathrm{~N}$ film and the Schottky barrier height of the diode. This can be explained by the increase of the work function with higher nitrogen content in the film.

\section{ACKNOWLEDGEMENTS}

The authors would like to acknowledge the assistance and support from National Science Council, and the Ministry of Economic Affairs, Taiwan, R.O.C., under the Contracts: NSC 96-2752E-009-001 and 95-EC-17-A-05-S1-020. The authors would also appreciate the measurement of the work function done by Ulvac Research Center, Taiwan.

\section{REFERENCES}

1. Y.-F. Wu, A. Saxler, M. Moore, R.P. Smith, S. Sheppard, P.M. Chavarkar, T. Wisleder, U.K. Mishra, and P. Parikh, IEEE Electron. Dev. Lett. 25, 117 (2004).

2. Y. Kokubun, T. Seto, and S. Nakagomi, Jpn. J. Appl. Phys. Part 2 40, L663 (2001).
3. Z. Lin, H. Kim, J. Lee, and W. Lu, Appl. Phys. Lett. 84, 1585 (2004).

4. H. Ishikawa, K. Nakamura, T. Egawa, T. Jimbo M. Umeno, Jpn. J. Appl. Phys. Part 2 37, L7 (1998).

5. Q.Z. Liu, L.S. Yu, F. Deng, S.S. Lau, and J.M. Redwing, J. Appl. Phys. 84, 881 (1998).

6. J. Kim, F. Ren, A.G. Baca, and S.J. Pearton, Appl. Phys. Lett. 82, 3263 (2003).

7. J.R. Hayes, D.-W. Kim, H. Meidia, and S. Mahajan, Acta Mater. 51, 653 (2003).

8. C.S. Lee, E.Y. Chang, L. Chang, C.Y. Fang, Y.L. Huang, and J.S. Huang, Jpn. J. Appl. Phys. 42, 4193 (2003).

9. T.N. Odera, P. Martin, J.Y. Lin, H.X. Jiang, J.R. Williams, and T. Isaacs-Smith, Appl. Phys. Lett. 88, 183505 (2006).

10. D.G. Park, C. Cabral Jr., O. Gluschenkov, and H. Kim, U.S. patent 7,023,064 (2006).

11. P.C. Jiang, Y.S. Lai, and J.S. Chena, Appl. Phys. Lett. 89, 122107 (2006).

12. D.A. Neamen, Semiconductor Physics \& Devices: Basic Principle, 2nd ed. (New York: McGraw-Hill, 1997).

13. C.D. Wagner et al., Handbook of X-ray Photoelectron Spectroscopy (Perkin-Elmer Physical Electronics Division, 1978).

14. The International Centre for Diffraction Data, Powder Diffraction File 25-1257 (unpublished).

15. C.C. Baker and S.I. Shah, J. Vac. Sci. Technol. A 20, 1699 (2002).

16. B.D. Cullity and S.R. Stock, Elements of X-ray Diffraction, 3rd ed. (Englewood Cliffs: Prentice-Hall, 2001). 